In the second place, the co-ordinate axes are supposed to be normal to one another. How is this normality to be defined? It is to be remembered that normality in Space-Time theory is a wider conception than normality in ordinary geometry; since in the former we have lines which are "selfnormal" (or what I have called "optical lines"), in addition to other rather curious features.

In the third place, the co-ordinate axes are supposed (if I may so express $j$ t), to be capable of graduation in equal parts. How is this graduation to be theoretically arrived at, and how are we to compare lengths, say along the axis of $x$, with lengths in some other direction?

It thus appears that we are reasoning in a circle if we attempt to give an analytical definition of Space-Time geodesics on such a basis.

The employment of generalised co-ordinates does not free us from difficulties, for, if it gets us out of one difficulty, it brings in another in its place.

Thus, for example, if the "graduations" were made according to arbitrary scales, the expression for the length of a Space-Time interval would contain functions the form of which would depend upon the arbitrary character of the scales employed. ${ }^{1}$

Again, if measurement of intervals be regarded as a fundamental conception, what is one to make of a case where

$$
\left(x_{1}-x_{2}\right)^{2}+\left(y_{1}-y_{2}\right)^{2}+\left(z_{1}-z_{2}\right)^{2}-\left(t_{1}-t_{2}\right)^{2}=0,
$$

in which $\left(x_{1}, y_{1}, z_{1}, t_{1}\right)$ and $\left(x_{2}, y_{2}, z_{2}, t_{2}\right)$ are the coordinates of two Space-Time points?

It must not be supposed that in raising these objections to the ordinary methods of treating this subject I am concerned only with destructive criticism.

My own answers to these difficulties are to be found in my published work.

In conclusion, I must thank Mr. Rogers for his very interesting letter published in NATURE of November 25; which, however, does not call for any special reply.

Cambridge, November 27.

Alfred A. RobB.

\section{A New Type of Electrical Condenser.}

SINCE an electrical condenser is a device for storing electricity, it follows that a secondary battery is a condenser-obviously of very large capacity as compared with the electrostatic type of condenser. Arguing from this point of view it appeared to the writer that, by a suitable arrangement of pasted lead grids immersed in dilute sulphuric acid and connected in circuit with an alternating current, it should be possible to obtain the characteristic effect of an electrical condenser, namely, a phase advance of the current relatively to the terminal potential difference.

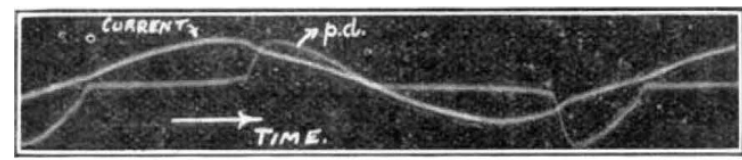

FIG. $x$.

A large number of tests have borne out this conclusion and it may be of interest to readers of NATURE to show an oscillogram of the effect (Fig. I). The oscillogram was taken during a test on a cell consisting of grids

2. This is the same sort of point which would arise, for instance, in thermodynamical theory by using some arbitrary scale of temperature nstead of the thermodynamic scale. pasted with red lead and immersed in dilute sulphuric acid. The temperature of the electrolyte was about $86^{\circ} \mathrm{C}$., the frequency of supply was 3.5 cycles per second, the current density about 0.75 amperes per square inch of grid and the r.m.s. value of the terminal pressure was a little more than 2 volts. There was practically no gassing of the cell during the test.

If the fundamental of the potential wave is determined it will be seen that there is a large angle of phase advance of the current on the pressure. There is one other interesting point noticeable in the oscillogram, namely, the potential difference of the grids remains relatively very small during a large portion of the current wave. When the current wave has passed its maximum value the pressure quickly rises to a maximum and then falls to zero at about the same moment as the current reaches its zero value. The process is then repeated during the next half of the current wave.

Edgar Allen Research Laboratory,

The University, Sheffield, November 25.

[AN engineering contributor to whom we have shown Dr. Walls" interesting letter writes: "It has been well known to electricians for the last thirty years that an electrolyte with metal plates in it will act as a condenser. These devices are called electrolytic condensers and are used in everyday work. They generally consist of aluminium plates immersed in an electrolyte, but iron plates in a solution of soda are sometimes used. They are useful for getting currents which lead in phase the supply voltage. Dr. Gunther Schulze carried out an extensive series of tests on electrolytic condensers at the Reichsanstalt in I909. See Elektrotechnik und Maschinenbau, 'Kondensatoren Grober Kapazität' (vol. xxvii. p. 247, I909)."-EDITOR, NATURE.]

\section{Sex of Irish Yew Trees.}

AFTER extensive inquiry up and down the country, I have so far failed to come across any example of the Irish Yew bearing male flowers. All the trees examined in private gardens and in cemeteries and churchyards have been of the berry-bearing or female sex.

I have now a number of young plants raised from the berries of the Irish Yew (Taxus fastigiata) fertilised by pollen from the English variety (Taxus baccata). "These show a graded series from the spreading English type to the erect Irish form.

Growth is so slow, however, that it will be some years before it will be possible to ascertain the sex of these plants; meanwhile, I should be glad to know through the readers of NATURE any case of a male Irish Yew.

If, as is believed, the Irish Yew trees now growing in England have all been propagated by cuttings from the mutational Irish form, which first appeared in Co. Fermanagh, Ireland, more than a hundred years ago, this would explain the fact that they are all of the female sex. On the other hand, it is desirable to ascertain whether any linkage originally existed between erect habit of growth and female-ness in the mutational Irish variety.

Further, if any male example of the Irish Yew can be discovered it would be desirable to test the effect of fertilising the female Irish Yew by Irish pollen.

Fernshaw, Springfield Road, Leicester, C. J. BOND. 